Check for updates

Cite this: Mater. Adv., 2022, 3, 3151

\section{Photophysical, electrochemical properties and flexible organic solar cell application of 7,7-bis(1-cyclopropyl carbonyl piperazino)-8,8 dicyanoquinodimethane $\dagger$}

\author{
Anwarhussaini Syed, (D) ${ }^{a}$ Renuka $\mathrm{H}$, (D) $^{\mathrm{b}}$ Anuradha Mohitkar, (D) ${ }^{\mathrm{a}}$ \\ Raghavaiah Pallepogu, (D ${ }^{c}$ Mahadev Sai Karthik Challa, (D) ${ }^{a}$ Sanket Goel (D) ${ }^{b}$ and \\ Subbalakshmi Jayanty (iD) *a
}

\begin{abstract}
Tetracyanoquinodimethane (TCNQ), when reacted with primary/secondary/simple aromatic amines, generates mono/di-substituted derivatives, predominantly manifesting in optical/non-linear optical properties. Nevertheless, the utilization of specific amines plays a critical role in terms of the materials aspects emerging from the diverse range of structures and unforeseeable properties. Surprisingly, demonstration of a TCNQ derivative with a simple, small amine moiety, emerging in organic solar cell applications has so far remained unexplored. Moreover, a knowledge gap still exists in terms of TCNQ derivatives. Accordingly, a thermally stable 7,7-bis(1cyclopropylcarbonyl piperazino)-8,8-dicyanoquinodimethane (BCCPDQ) fluorophore was successfully attained in a one-step effortless synthesis using 1-(cyclopropylcarbonyl)piperazine. Solid BCCPDQ displays enhanced fluorescence $\left(\Phi_{\mathrm{f}}=\sim 10 \%\right)$ compared to in solution $\left(\Phi_{\mathrm{f}}=\sim 0.30 \%\right)$. The electrochemical band gap $(\sim 2.67 \mathrm{eV})$ was found to be in good agreement with the optical band gap $(\sim 2.68 \mathrm{eV})$. Furthermore, BCCPDQ exhibits organic flexible solar cell device capability, noted for the first time among TCNQ derivatives. The heterostructure device embedded with $\mathrm{TiO}_{2}$ nanoparticles tested for various photovoltaic (PV) parameters displays excellent stability, with an efficiency of around $2.26 \%$. The electrical characteristics of the device on a flexible substrate did not degrade under various bending conditions, and the acquired findings correspond well with the zero stress device, demonstrating the exceptional stability of the PV and its potential for use in wearable and flexible electronics. To gain a greater understanding on the mechanism involved, the PV characteristics were described using a band diagram. Consequently, this study represents a cutting-edge method in understanding a new tiny organic molecular material and integrating it into a flexible solar cell.
\end{abstract}

Received 30th August 2021, Accepted 12th February 2022

DOI: $10.1039 / \mathrm{d} 1 \mathrm{ma} 00778 \mathrm{e}$

rsc.li/materials-advances as diaminodicyanoquinodimethanes (DADQs), which have push-pull characteristics. D- $\pi-\mathrm{A}$ disposition facilitates the interaction of a donor (D) and an acceptor (A) across a $\pi$ system, referred to as intramolecular charge transfer (ICT). TCNQ shows a strong tendency to form charge transfer (CT) complexes/adducts. ${ }^{1-3}$ Interestingly the selection of the amine plays a significant role in fine tuning the well-defined structure of the material, accompanied by the fascinating and unpredictable properties of the different DADQs formed, which makes them a good research focus. This results in the production of materials that have a diverse range of applications, such as organic semiconductors ${ }^{4}$ and molecular hopper crystals, ${ }^{5}$ as well as non-linear optical ${ }^{6,7}$ and mechanochromic materials. ${ }^{8}$

Di-substituted TCNQ derivatives ${ }^{9-11}$ usually display enhanced fluorescence in their solid form owing to the hydrophobic nature, and can be converted into CT complexes/salts for bio-imaging purposes. ${ }^{12-14}$ In this context, piperazine derivative (DPZDQ) and its $p$-toluenesulphonic acid (PTSA) salt $\left(\mathrm{BT}_{2}\right)$ have been exclusively 
studied on account of the staining of the cell wall and nuclei in epidermal/stomata cell imaging (in dicotyledon plant leaves), ${ }^{12}$ as well as for selective bacterial endospore imaging. ${ }^{13}$ Of late, contrastingly, hydroxyethylpiperazine derivatives (BHEPDQ fluorophores) have exhibited flexible organic resistive memory switching device applications, ${ }^{15}$ as undertaken by our group. Moreover, incorporating aromatic carbonyls/heteroatoms with a lone pair of electrons into the structures proved useful in the development of phosphorescent materials, wherein, generally heavy atoms are included as substituents. ${ }^{16}$ Nevertheless, this has been achieved in TCNQ derivatives by introducing an amine with a carbonyl functionality between a piperazine and phenyl ring, viz. $N$-benzoylpiperazine. Thus, 7,7-bis( $N$-benzoylpiperazino)-8,8-dicyanoquinodmethane $(B B P D Q)^{17}$ reveals solid state phosphorescence.

A prototype molecule possessing a imidazolidine moiety as a linking diaminomethylene group, reported in 1962, has been theoretically studied and proposed for non-linear optics and solar cell applications. ${ }^{18,19}$ Nevertheless, it has never been isolated, neither in its pure form nor characterized structurally. DADQs that have been structurally characterized are typically mono/di-substituted TCNQ derivatives, i.e., with an unlinked diaminomethylene moiety. Surprisingly, to date, the solar cell properties of DADQs have not yet been investigated. Recent developments in optoelectronics have demonstrated that organic materials-based platforms can surpass Si-based devices in terms of their photovoltaic (PV) applications. Lately, organic solar cells (OSCs) have been able to achieve a power conversion efficiency (PCE) of around 18\% via the interfacial and device engineering of bulk heterojunctions (BHJ). ${ }^{20,21}$ However, the commercial realization of tandem structures has been hindered due to their low output voltage and unstable active layers, which in turn lead to a deterioration in device performance.

However, small-molecule organic solar cells are gaining interest owing to their chemically-tuned broad spectral ranges resulting from their conjugated structures, as well as their easy functionalization. ${ }^{22}$ The advantages of integrating small molecules into PV systems involve simple designs, higher integration density, low cost processing and superior mechanical stability, making them ideal for flexible applications. ${ }^{15}$ Dye and BHJs based organic PVs developed with fullerene-based derivatives have been much celebrated, however they exhibit weak absorbance, reduced tenability, and device instability, which has prompted further research towards the development of small molecule organic materials that have been less explored and the progress of which has been comparatively slow. ${ }^{23-25}$ In particular, TCNQ and its derivatives have been successfully applied as dopants to facilitate charge injection and enhanced carrier transportation in various optoelectronic devices. ${ }^{25,26}$ Liu et al. and Zhang et al., ${ }^{26,27}$ demonstrated the p-doping of $\mathrm{F}_{4}$-TCNQ (tetrafluoro-7,7,8,8-tetracyanoquinodimethane) in PCDTBT:PC70BM and P3HT:ICBA (poly(3-hexylthiophene):indene-C60 bis adduct) bulk heterojunctions, respectively, and achieved remarkably improved photovoltaic response. Furthermore, Guillain et al. developed a thermally diffused TCNQ-doped active layer for polymer solar cells to facilitate higher charge extraction efficiency. ${ }^{28}$ Nevertheless, mainly due to diffusion and crystallization of the active layers, thermal annealing can lead to the critical failure of solar cells. Moreover, solar cells often feature indium tin oxide (ITO) coated glass, a rigid bottom substrate that cannot withstand high annealing temperatures, which is also not suitable for flexible electronic applications. Recently, flexible solar cells have gained more attention compared to rigid solar cells owing to their robustness and promising potential for use in wearable or textiles or space compatible electronic applications. ${ }^{29,30}$ Moreover, only a few reports on small molecules with a flexible platform have been demonstrated to date, which necessitates further exploration in this direction. Efforts have been devoted to exploring PV properties based on standalone 7,7-bis(1-cyclopropylcarbonylpiperazino)8,8-dicyanoquinodimethane (BCCPDQ) and a tandem structure comprising a $\mathrm{TiO}_{2}$ electron transport layer.

Since small molecules based flexible organic device applications have yet to be explored with DADQs, herein a distinct TCNQ derivative, BCCPDQ, has been designed, synthesized and developed, realizing it to be not only a solid state emitter, and thermally and photochemically stable (a well-known feature), but with it also exhibiting solar cell responsive properties (a unique feature). BCCPDQ was thoroughly characterized using a variety of spectroscopic techniques. A crystal structure study revealed interesting and diverse features in terms of extensive short contacts/intermolecular hydrogen bonding, especially due to water and DMF molecules being arranged adjacent and sandwiched between the BCCPDQ molecular dipoles. This led to the formation of supramolecular assemblies, leading to enhanced fluorescence in the solid state $\left(\lambda_{\text {max,emi }}=528 \mathrm{~nm}\right)$. Higher Stokes shifts $(95-100 \mathrm{~nm})$ were also observed in various solvents. BCCPDQ was found to be thermally stable up to $\sim 250{ }^{\circ} \mathrm{C}$.

To date, solid state/ultrathin coated fluorescent materials have made a great impression on optoelectronic devices, with uses in organic solid-state lasers, ${ }^{31,32}$ light emitting diodes (OLEDs), ${ }^{33,34}$ sensors, $^{35,36}$ and security print systems. ${ }^{37,38}$ Furthermore, TCNQ, due to its strong crystallinity in the thin film state, has shown high absorbance in its visible spectrum. Besides this, its photoluminescence (PL) quenching has confirmed its efficient photo-induced charge transfer. However, TCNQs have been shown to exhibit a high recombination rate due to the presence of leakage currents in the active region. ${ }^{39}$ Therefore, it is necessary to achieve an optimized film morphology with better phase separation, which can lead to a higher power conversion efficiency in the solar cell. In order to fabricate a solar cell with reduced recombination losses we have incorporated an electron transport layer $\left(\mathrm{TiO}_{2} \mathrm{NPs}\right)$ in the cell that not only influences charge transfer and collection, but also behaves as a hole blocking layer to suppress electron-hole recombination at the interface. The high electron mobility (0.1-10 $\left.\mathrm{cm}^{2} \mathrm{~V}^{-1} \mathrm{~s}^{-1}\right)$ and deeper conduction band match well with the BCCPDQ structure, which brings about more chemical stability to the PV device.

Thus, in this article, efforts have been devoted to explore the PV properties of 7,7-bis(1-cyclopropylcarbonylpiperazino)8,8dicyanoquinodimethane (BCCPDQ) by presenting its fabrication, characterization and comprehensive study on its 
fluorescence, electrochemical and electrical properties, with the flexible solar cell application of a simple and small organic molecule, BCCPDQ, shown along with a tandem heterojunction formed with $\mathrm{TiO}_{2}$. As $\mathrm{TiO}_{2}$ plays an important role in the extraction of trapped carriers from the interface, the charge collection efficiency improved, thus we achieved a higher PCE of $2.26 \%$ in contrast to the standalone BCCPDQ PV device that had the limitation of carriers being trapped and later recombining in the active region. Hence, we believe these properties can lead to power generation solutions for flexible and wearable electronics.

\section{Experimental section}

\subsection{Materials and methodology}

7,7,8,8-Tetracyanoquinodimethane (TCNQ) and 1-(cyclopropyl carbonyl) piperazine were procured from TCI Chemicals (India) Pvt. Ltd. TCNQ was recrystallized from acetonitrile, while the amine was used without further purification. Pyridine (as a catalyst) was purchased from Spectrochem. Acetonitrile (MeCN) and dimethylformamide (DMF) (HPLC grade) were purchased from Sisco Research Laboratories Pvt. Ltd.

Using a JASCO FT/IR-4200 spectrometer (400-4000 $\left.\mathrm{cm}^{-1}\right)$, infrared (IR) stretching frequencies were recorded using $\mathrm{KBr}$ pellets. The ${ }^{1} \mathrm{H}$ and ${ }^{13} \mathrm{C}$ nuclear magnetic resonance (NMR) spectra were recorded on a Bruker Avance Neo-400 spectrometer using DMSO- $\mathrm{d}_{6}$ (peak at $2.55 \mathrm{ppm}$ in the ${ }^{1} \mathrm{H}$ NMR spectra and $39.5 \mathrm{ppm}$ in the ${ }^{13} \mathrm{C}$ NMR spectra) as a standard solvent. Mass spectra $(\mathrm{m} / \mathrm{z})$ were detected using a Shimadzu spectrometer in electrospray ionization (ESI) mode. An absorption study was carried out on a V-670 UV-Vis-NIR spectrophotometer (JASCO). Optical band gaps were calculated by carrying out a diffuse reflectance study (DRS) on a JASCO V-670 UV-visible spectrophotometer, by using the Kubelka-Munk method. Fluorescence quantum yields of the solutions were determined in comparison to quinine sulfate in $1 \mathrm{~N} \mathrm{H}_{2} \mathrm{SO}_{4}(\phi=0.546),{ }^{40}$ where the absolute quantum yields of solid samples were estimated using a corrected integrated sphere with an absolute error of $0.02 \%$, on a Horiba scientific Fluorolog instrument and the photoluminescence quantum yield (PLQY) calculator of the v.3 software. Lifetime measurements were carried out on timecorrelated single photon counting instrument (Deltaflex Horiba scientific). A weight loss study was conducted via differential thermal gravimetric analysis on a DTG-60 instrument (Shimadzu).

\subsection{Synthesis and characterization}

7,7-Bis(1-cyclopropylcarbonyl)piperazino-8,8-

dicyanoquinodimethane (BCCPDQ) was synthesized by minor modification of a reported procedure. ${ }^{41}$ 1-(Cyclopropylcarbonyl) piperazine $\left(0.316 \mathrm{~g}, 2.0 \mathrm{mmol}\right.$ ) was added under a $\mathrm{N}_{2}$ atmosphere to a hot solution of TCNQ (0.2 g, $0.979 \mathrm{mmol})$ dissolved in acetonitrile at $75{ }^{\circ} \mathrm{C}$. After $10 \mathrm{~min}$, a catalytic amount of pyridine (Py) was added to the reaction mixture at $75{ }^{\circ} \mathrm{C}$ and the temperature was raised to $100-105{ }^{\circ} \mathrm{C}$ for $2 \mathrm{~h}$, and then subsequently increased to $\sim 120{ }^{\circ} \mathrm{C}$ for $1 \mathrm{~h}$. After completion of the reaction, the reaction mixture was cooled to $\sim 30{ }^{\circ} \mathrm{C}$ and allowed to stand for 2 days under a $\mathrm{N}_{2}$ atmosphere, whereafter a yellow precipitate settled at the bottom of the reaction vessel. The crude yellow compound was then filtered and washed with cold acetonitrile, dissolved in DMF, and extracted with diethyl ether, a process that was repeated twice. Eventually, pure yellow BCCPDQ (Scheme 1) powder was obtained, which was further crystallized from DMF.

FT-IR (KBr pellet): $\nu_{\max } / \mathrm{cm}^{-1}: 2171,2134$ (substituted nitrile stretch), 1643 (amide carbonyl stretch), 1592 (aromatic $\mathrm{C}=\mathrm{C}$

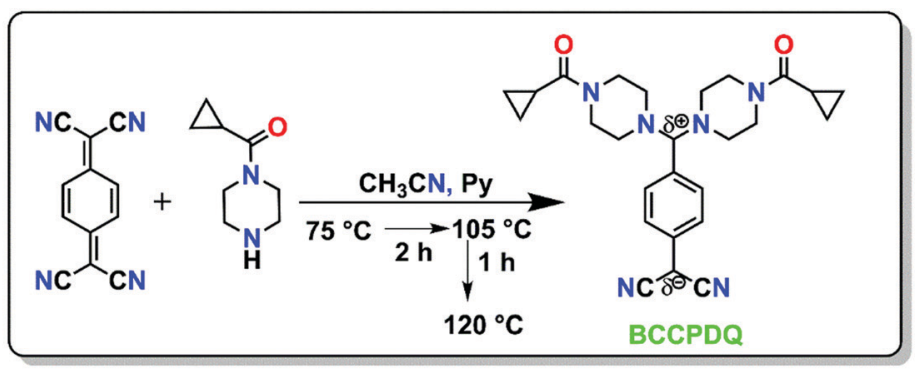

Plausible mechanism:

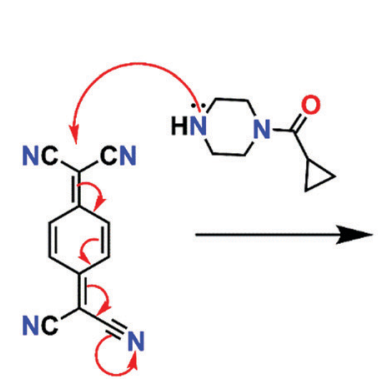

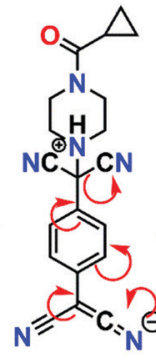

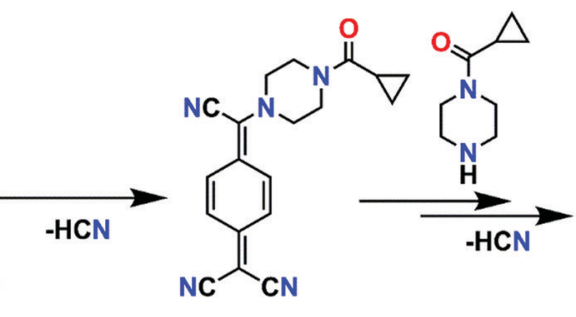

Scheme 1 Reaction scheme and plausible mechanism for the formation of BCCPDQ. 
stretch), 1313 (C-N stretching). $\delta \mathrm{H}^{1}$ (ppm) NMR (400 MHz; DMSO d $\left._{6} ; \mathrm{Me}_{4} \mathrm{Si}\right): 7.42(2 \mathrm{H}, \mathrm{d}, \mathrm{Ar}, J=8.6 \mathrm{~Hz}), 6.89(2 \mathrm{H}, \mathrm{d}, \mathrm{Ar}, J=$ $8.7 \mathrm{~Hz}$ ), 3.90-3.67 (16H, unresolved multiplicity), 2.09-1.98 $(2 \mathrm{H}$, unresolved multiplicity), 0.77 (8H, unresolved multiplicity). $\delta$ $\mathrm{C}^{13}$ NMR (101 MHz, DMSO): 171.89, 150.47, 132.63, 123.29, 118.82, 118.43, 114.01, 51.60, 51.22, 35.34, 10.71, 7.75. Mass $(\mathrm{m} / \mathrm{z}): 481(\mathrm{M}+\mathrm{Na})$ in ESI mode (Fig. S1(a)-(c)) (ESI $\dagger)$.

\subsection{Single-crystal X-ray diffraction}

Suitable crystals were selected under a microscope and mounted on Rigaku Oxford XtaLAB Pro: Kappa dual offset/far diffractometer. Crystal data was acquired and noted at $293(\mathrm{~K})$ using a MoK $\alpha(0.71073 \AA)$ radiation source employing spherical harmonics, and then an empirical absorption correction was implemented using a SCALE3 ABSPACK scaling algorithm. The structure was solved using Olex $2,{ }^{42}$ accompanied by the ShelXS ${ }^{43}$ structure solution program with intrinsic phasing, and then refined using the ShelXL ${ }^{44}$ refinement package via least squares minimisation.

\subsection{Electrochemical properties}

Cyclic voltammetry (CV) was accomplished using a CHI 619d (CH International, USA) electrochemical analyzer with a conventional three-electrode system. A glassy carbon electrode (GCE) with a $3 \mathrm{~mm}$ diameter $\left(0.07 \mathrm{~cm}^{2}\right.$ electrode surface area) was used as a working electrode, $\mathrm{Pt}$ wire as a counter electrode and $\mathrm{Ag} \mid \mathrm{AgCl}$ as the reference electrode. The GCE was polished carefully with $1,0.3$, and $0.05 \mathrm{~mm}$ alumina powder sequentially until a mirror finish was obtained. Subsequently, the electrode was washed with a water and ethanol mixture, and then with acetone several times, before being finally dried in air at room temperature.

\subsection{Scanning electron microscopy (SEM)}

BCCPDQ solutions were prepared in solvents with varying polarities and drop cast on silicon wafers. The silicon wafers were cleaned thoroughly with water, soap solution and acetone, and dried in an oven at $\sim 100{ }^{\circ} \mathrm{C}$ for $1 \mathrm{~h}$ prior to being sputtered with gold (4 nm thickness), and studied under an Oxford X-max LEICA EM ACE200 SEM at an operating voltage of $10 \mathrm{kV}$.

\subsection{Fabrication process}

To fabricate the Al/BCCPDQ/ITO PET PV device, chemically synthesized BCCPDQ was dissolved in DMF to prepare a $1 \mathrm{mM}$ solution, which was then spin coated on ITO coated PET (bottom substrate/cathode) at $500 \mathrm{rpm}$ for $30 \mathrm{~s}$. Consequently, the sample was dried at room temperature. To develop a top electrode/anode, aluminum (Al) was deposited using a masking procedure via e-beam evaporation. To fabricate the tandem organic solar cell, $\mathrm{TiO}_{2}$, which behaves as an electron transport layer, was spin-coated on the ITO-coated PET (bottom substrate/cathode). The sample was then dried at room temperature. Subsequently, a BCCPDQ layer was coated on the $\mathrm{TiO}_{2} /$ ITO-coated PET substrate and dried under ambient conditions. Al electrodes were deposited on top of the BCCPDQ layer to form the anode.
The current density-voltage $(J-V)$ characteristics of the OSC devices were determined using a Keysight B2912A-source measuring tool. The voltage was swept from -1 to 1 , maintaining a sweep count of 100 . Using a PET Model \#SS0AAA Solar Simulator class instrument, electrical characteristics were derived under simulated sunlight of 1 sun $\left(100 \mathrm{~mW} \mathrm{~cm}^{-2}\right.$, AM $1.5 \mathrm{G}$ irradiation).

\section{Results and discussion}

The attained BCCPDQ was thoroughly characterized and confirmed using a variety of spectroscopic techniques, as mentioned above. Subsequently, detailed investigations were carried out on its crystal structure, photophysical and electrochemical properties, and solar cell applications.

\subsection{Crystallographic analysis}

Thermally stable shiny greenish-yellow blocks of BCCPDQ were grown in DMF under slow evaporation at room temperature over 3 to 4 days, crystallizing in a triclinic system in the $P \overline{1}$ space group. The asymmetric unit comprises one full molecule of BCCPDQ, DMF and four $\mathrm{H}_{2} \mathrm{O}$ molecules. Notably, until now, only two DADQs (with aromatic amine substituents) have been crystallized along with DMF/water: (i) 2-methyl-4-chloroaniline substituted $\mathrm{DADQ}^{41}$ with a half molecule of DMF and one molecule of water and (ii) 4-chloroaniline di-substituted dicyanoquinodimethane ${ }^{45}$ with two DMF molecules in its asymmetric unit. In both structures, extensive non-covalent interactions like those in the current BCCPDQ structure were not observed. The Ortep molecular structure diagram of the obtained sample with $50 \%$ probability thermal ellipsoids is shown in Fig. S2 (ESI $\dagger$ ) and the basic crystallographic data are provided in Table S1 (ESI $\dagger$ ). Details of data collection, solution and refinement, along with the CIF files, can be found in the $\mathrm{ESI} \dagger$ (Tables S2-S6). The molecular structure of BCCPDQ shows that the central ring (C1-C6) is almost benzenoid in nature, with an average carbon-carbon bond distance of $1.3895 \AA$. Intramolecular charge transfer occurred from the diaminomethylene to the dicyanomethylene unit to result in the formation of a zwitterionic structure. ${ }^{45,46}$ The diaminomethylene unit was found to be twisted with reference to the benzenoid ring plane with torsion angles of $\tau_{\mathrm{N} 5-\mathrm{C} 10-\mathrm{C} 4-\mathrm{C} 5}=45.71^{\circ}$ and $\tau_{\mathrm{N} 3-\mathrm{C} 1-\mathrm{C} 4-\mathrm{C} 3}=45.20^{\circ}$, with an average of $45.46^{\circ}$, which is slightly less than that of BBPDQ $\left(\sim 48^{\circ}\right)$, probably due to the flexible substituent cyclopropyl carbonyl (current work) when compared to the phenyl carbonyl in BBPDQ. ${ }^{17}$ Fluorescence enhancement can be achieved by tuning the molecular torsional angle. ${ }^{47}$ Interestingly four water and two DMF molecules were found to be sandwiched between the molecular dipoles (Fig. 1(a)), and engaged in the extensive short contacts/hydrogen bonding (Fig. 1(b) and Fig. S3(a), ESI †), forming a network. The distance between the carbonyl oxygen of one molecular dipole and the diaminomethylene carbon of the neighbor is $3.454 \AA\left(r_{\mathrm{O} \cdots \mathrm{C}}=3.454 \AA\right)$, indicating a significant electrostatic interaction, with a corresponding $\mathrm{H}$-bond distance of $2.477 \AA$, 

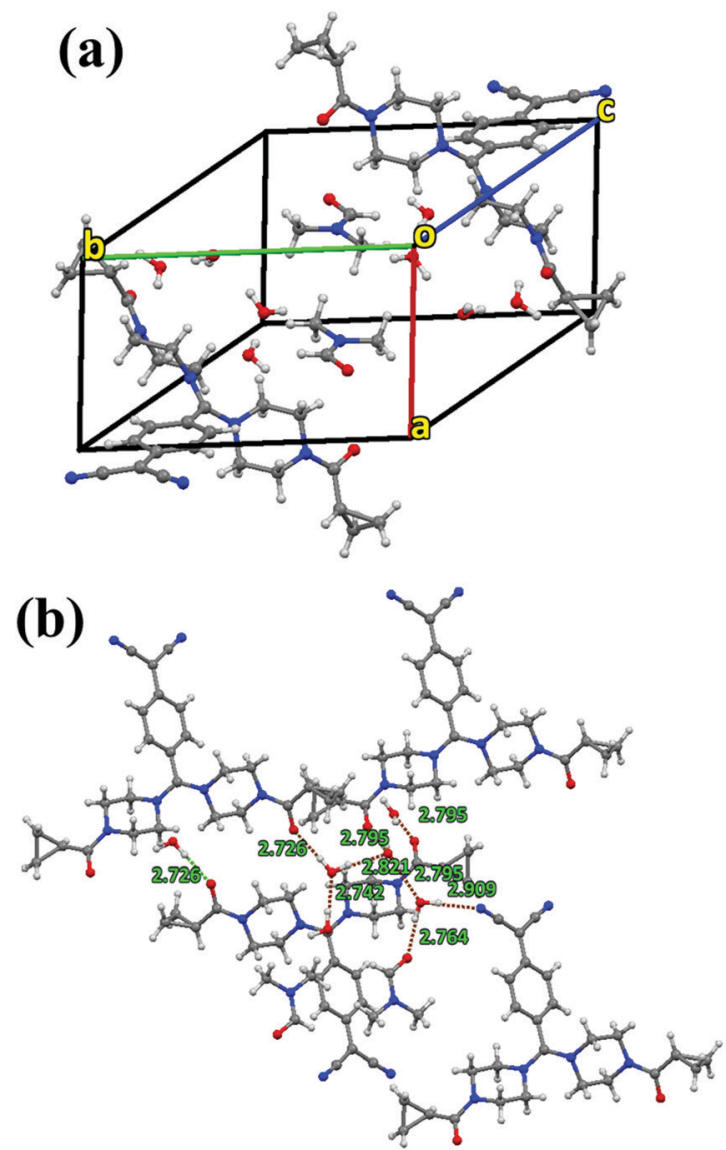

Fig. 1 Molecular packing diagrams showing (a) four $\mathrm{H}_{2} \mathrm{O}$ and two DMF molecules sandwiched between the BCCPDQ molecular dipoles. (b) Extensive $\mathrm{H}$-bonding was noted, especially among water molecules, the free $\mathrm{C} \equiv \mathrm{N}$ of $\mathrm{BCCPDQ}$ and the carbonyl group of the amine.

thereby leading to supramolecular assembly (Fig. S3(b), ESI $\dagger$ ). Only one intramolecular interaction $(\mathrm{O} 1 \cdots \mathrm{H} 18 \mathrm{~B}=2.664 \AA)$ was observed between the carbonyl oxygen (O1) and methylene hydrogen (H18B) of the cyclopropyl ring. Water molecule arrays were noted along the $a b$ plane, with parallel and antiparallel arrays of molecular dipoles along the $c$ axis (Fig. S3(a), ESI $\dagger$ ) and DMF moieties oriented antiparallel to each other along the $b$ axis (Fig. S3(b), ESI $\dagger$ ).

A crystal structure study predominantly revealed the existence of short intermolecular interactions $(<$ sum of the van der Waals radii of the atoms), with a minimum number of hydrogen bond type interactions. Significant non-covalent intermolecular interactions $(\AA)$ and H-bond type interactions ranged from weak to moderate to strong, exemplifying the orientations of the molecular dipoles, as described in detail in Table S7 (ESI $\dagger$ ). Some notable short contacts (primarily within the range of 2.50-3.20 $\AA$ ) were observed between the BCCPDQ dipoles, water and DMF molecules. Surprisingly, all the $\mathrm{O}$ atoms of the water molecules $(\mathrm{O} 4, \mathrm{O} 5, \mathrm{O} 6$ and $\mathrm{O} 7)$ underwent intermolecular interactions with each other or with carbonyl oxygens (O1, O2) viz. O1-O6; O2-O5; O3-O4; O4-O5; O5-O6 and O6-O7, except for $\mathrm{O} 4$ and $\mathrm{O} 7$, which were not involved in any interactions.
Benzenoid rings were separated by a centroid distance of 7.236 ̊. Water and DMF were found to be trapped between the BCCPDQ moieties, preventing interactions between individual dipoles, leading to $\mathrm{H}$-bond interactions with water and DMF. Interestingly, one N1, N2 (of free $\mathrm{C} \equiv \mathrm{N}$ ) were involved in intermolecular interactions, and notably, nitrogens of piperazine (N3, N4, N5 and N6) that were under strain and conjugated with carbonyls were thus not involved in any inter/intramolecular interactions. Yet, only four types of substituted piperazines have been reacted with TCNQ, namely; phenyl carbonyl piperazine, ${ }^{17} \mathrm{~N}$-methyl piperazine, ${ }^{48}$ cyanophenyl piperazine, ${ }^{49}$ and hydroxyethyl piperazine,${ }^{15}$ wherein such type of solvents interactions in crystallization was unknown. Furthermore, only the (phenyl carbonyl) piperazine derivative of TCNQ exhibited mechanochromic phosphorescence features due to its carbonyl moiety. However, herein, probably the cumulative effect of rigorous intermolecular interactions accompanied by two DMF and four water molecules in the crystal lattice of BCCPDQ along with the presence of the carbonyl functionality steered the enhancement in the fluorescence, resulting in the manifestation of solar cell properties, noted for the first time among the TCNQ derivatives studied so far.

\subsection{Photophysical properties}

Absorption and emission spectra of solutions of the sample were recorded in solvents with varying polarity by maintaining similar optical density. Considerable solvatochromism was not observed for the solutions (Fig. 2(a) and (b)), however, a slight blue shift was noted in $\mathrm{MeCN}\left(\lambda_{\max , \mathrm{abs}}=430 \mathrm{~nm}\right), \mathrm{MeOH}$ $\left(\lambda_{\text {max }, \mathrm{abs}}=423 \mathrm{~nm}\right), \mathrm{EtOH}\left(\lambda_{\text {max }, \mathrm{abs}}=432 \mathrm{~nm}\right), \mathrm{DMF}\left(\lambda_{\max , \mathrm{abs}}=\right.$ $431 \mathrm{~nm})$ and DMSO $\left(\lambda_{\text {max,abs }}=425 \mathrm{~nm}\right)$ with respect to IPA $\left(\lambda_{\text {max }, \text { abs }}=442 \mathrm{~nm}\right)$. The $\lambda_{\text {max,emi }}$ was $\sim 529 \mathrm{~nm}$ in all of the solvents considered in this study. Details of the wavelengths of absorption, emission, Stokes shifts and quantum yields in solution and solid state are presented in Table S8 (ESI $\dagger$ ). The lowest energy absorptions are likely due to intramolecular charge-transfer transitions, a feature that is characteristic of DADQs. ${ }^{44,45}$ The relative shifts in the absorption compared to the emission spectra revealed a larger dipole moment in the ground electronic state.

The emission intensity was the highest in IPA $\left(\sim 14 \times 10^{4}\right.$, viscosity $(\eta)$ in centipoise $=2.04)$ followed by DMSO $\left(\sim 13 \times 10^{4}\right.$, $\eta=1.99) ; \operatorname{EtOH}\left(\sim 9 \times 10^{4}, \eta=1.07\right) ; \operatorname{DMF}\left(\sim 7 \times 10^{4}, \eta=0.79\right)$; $\mathrm{MeOH}\left(\sim 5 \times 10^{4}, \eta=0.54\right)$; and $\operatorname{MeCN}\left(\sim 2.3 \times 10^{4}, \eta=0.37\right)$ (Table S9 (ESI $\dagger)$ ); possibly suggesting a role of viscosity. Interestingly, the emission intensity declined gradually with a decrease in viscosity. A controlled experiment performed in IPA at varying temperatures revealed strong fluorescence at low temperatures $\left(0{ }^{\circ} \mathrm{C}, 5{ }^{\circ} \mathrm{C}, 10{ }^{\circ} \mathrm{C}\right.$ and $\left.15{ }^{\circ} \mathrm{C}\right)$ than at ambient temperatures $\left(20{ }^{\circ} \mathrm{C}, 25{ }^{\circ} \mathrm{C}, 30{ }^{\circ} \mathrm{C}\right.$ ) (Fig. S4, ESI $\dagger$ ). Furthermore, the role of viscosity was also confirmed by using a waterglycerol mixture, wherein enhanced fluorescence emission was observed upon an increase in the quantity of glycerol (Fig. S5, ESI $\dagger$ ). 

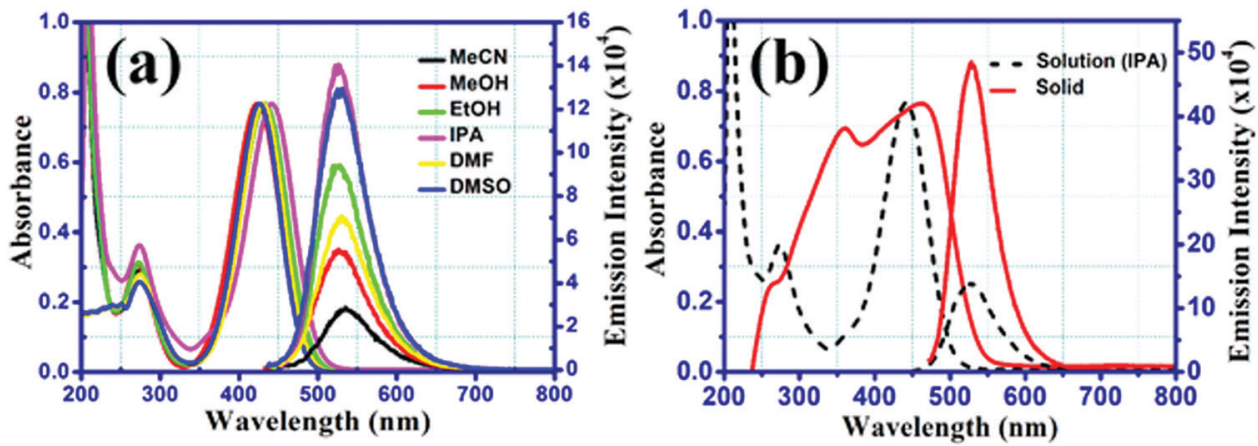

Fig. 2 (a) The absorption (left side) spectra show no significant solvatochromism, and the emission (right side) spectra indicate a similar $\lambda_{\text {max,emi }} \sim$ $529 \mathrm{~nm}$ in solvents with different polarities, conveying that the emission is from a similar locally excited state. (b) Enhanced emission in the solid state compared to in solution (in i propyl alcohol-IPA).

The role of viscous solvents and polymer matrices in the enhancement of light emission on asymmetric di-substituted DADQ has been studied by Bloor et al. ${ }^{50} \mathrm{~A}$ decrease in the emission intensity in $\mathrm{MeCN}, \mathrm{MeOH}$, and DMF compared to in IPA, DMSO, and EtOH could be due to the overlap of the $\mathrm{S}_{1} / \mathrm{T}_{1}$ vibronic modes with $\mathrm{S}_{0} .{ }^{51}$ The sample in the solid state exhibited a higher absorption wavelength and rather broad features. The major shift in the absorption of the solid $(464 \mathrm{~nm})$ compared to the solution $(\sim 431 \mathrm{~nm})$ probably indicates the existence of strong intermolecular interactions and exciton coupling effects in the former. Interestingly, the excited state still remained the same $\left(\lambda_{\text {max }, \text { emi }}=528 \mathrm{~nm}\right)$. In particular, similar $\lambda_{\max }$ emission in both the solution and solid state suggest that the emission arises from the identical local excited state. ${ }^{44}$ Even though it is difficult to quantify rigorously that the emission arises due to the solid state, as a result of factors such as scattering, reflection and possible wave-guiding effects, the spectra in Fig. 2(b) illustrate a clear $\sim 4$ fold fluorescence enhancement in the data of the solid compared with the solution. Such an effect in the solid state may be attributed to the suppression of relaxation from the vertical excited state to a non-emitting state. ${ }^{51,52}$ Also, the factor that contributes towards the suppression of relaxation in the solid is crystallization induced. Therefore, the increase in the emission intensity in the solid can be ascribed to H-bonding interactions leading to supramolecular assembly rather than to an aggregation phenomenon. Furthermore, to a $10 \mathrm{ppm}$ BCCPDQ solution in DMSO, a 0 to $90 \%$ Millipore (18 M $\Omega$ ) water fraction $\left(f_{\mathrm{w}}\right)$ was added, and the emission intensity markedly decreased from $20 \% f_{\mathrm{w}}$, indicative of aggregation quenching (Fig. S6, ESI $\dagger$ ). Hence, the overall effect of the extensive non-covalent interactions along with the H-bonded network lead to the supramolecular assembly exhibiting fluorescence enhancement in the solid. The push-pull mechanistic effect from the amine to the benzenoid skeleton leading to the zwitterionic nature of a fluorophore initiates supramolecular assembly in the solid state $^{53}$ The quantum yield was higher in DMSO and IPA $(\sim 0.31 \%)$, where the absolute quantum yield for a solid was found to be $\sim 10 \%$ (Table S8, ESI $\dagger$ ). The chromaticity output diagram with obtained color coordinates of $x, 0.364$ and $y$,
0.606 relevant to the emission $\lambda_{\max } \sim 528 \mathrm{~nm}\left(\lambda_{\text {exc }} 464 \mathrm{~nm}\right)$ is shown in (Fig. 3(a)). BCCPDQ manifests a yellow colour under ambient light and greenish emission under long UV light (365 nm) (Fig. 3(b) and (c)).

Very recently, in 4-(4-aminophenyl)morpholin-3-one (APM), mono/di-substituted TCNQ derivatives, namely APMTQ and BAPMDQ $^{54}$ developed in our laboratory, exhibited fluorescence enhancement in solutions with $\lambda_{\max }$ emissions of $634 \mathrm{~nm}$ for APMTQ (mono substituted), $564 \mathrm{~nm}$ for BAPMDQ (disubstituted) when compared to in the solid state. Moreover, unprecedented exclusive solid-state cation recognition, as a consequence of extended conjugation and cation- $\pi$ interaction, was identified. Presently, the design of pure organic small molecules as solid-state emitters is still a continuing challenge, with BCCPDQ among them.

The fluorescence lifetime decay in the solid state was found to be $\sim 0.26 \mathrm{~ns}$, (Fig. S7, ESI $\dagger$ ) on account of the strong zwitterionic nature and stability of the excited state, resulting in fewer non-radiative decay channels. ${ }^{41,54}$ Decay fitting was achieved using the third pre-exponentials and the accuracy of the fitting was checked by judging the chi square $\left(\chi^{2}\right)$ value (Table S10, ESI $\dagger$ ), while the solution showed no significant decay. The measurable lifetime exhibited by the solid could

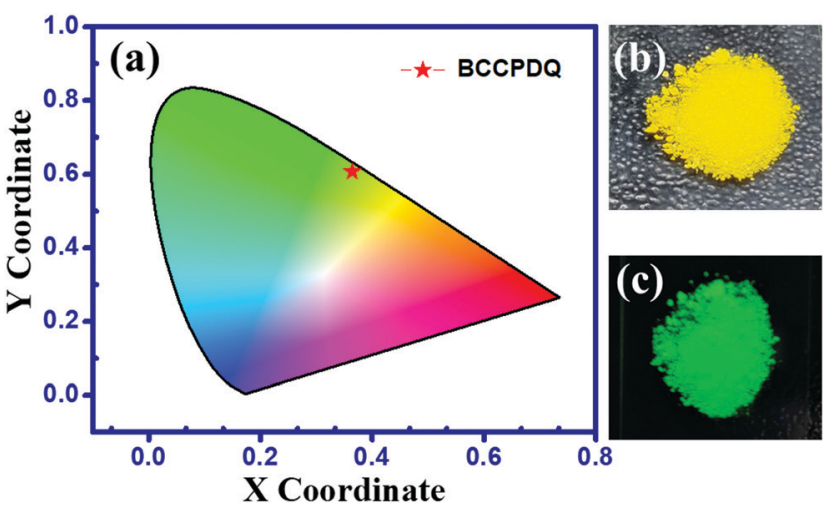

Fig. 3 (a) Chromaticity diagram of BCCPDQ, (b) under ambient light, and (c) under long UV light (365 nm). 
also likely be attributed to its higher quantum yield (Table S8, ESI $\dagger$ ).

\subsection{CV studies}

$\mathrm{CV}$ measurements were executed in $0.1 \mathrm{M}$ tetrabutylammonium perchlorate in acetonitrile containing $10 \mu \mathrm{M}$ of BCCPDQ solution at a scan rate of $25 \mathrm{mV} \mathrm{s}^{-1}$ (Fig. 4(a)). A scan rate dependent study was conducted at different scan rates, starting from $10 \mathrm{mV} \mathrm{s}^{-1}$ to $100 \mathrm{mV} \mathrm{s}^{-1}$ (Fig. 5(a)). Three quasi-reversible reduction waves with a half-wave potential $E_{1 / 2}$ at $-0.11 \mathrm{~V}$, $-0.91 \mathrm{~V}$, and $-1.293 \mathrm{~V}$ (vs. $\mathrm{Ag} / \mathrm{AgCl})$ there observed due to three consecutive reductions of dicyano methylene end groups into the corresponding radical anions. ${ }^{55}$ Besides the reduction, three irreversible oxidation peaks were revealed at $E^{\text {ox }}$ value of $0.67 \mathrm{~V}, 1.06 \mathrm{~V}$, and $1.377 \mathrm{~V}$, ascribed to the presence of the donor (1-cyclopropyl carbonyl)piperazine functionality in BCCPDQ. The oxidation peak might be assigned to the oxidation of two nitrogens of piperazine adjacent to the $\delta^{+}$carbon and one nitrogen attached to the carbonyl group. The oxidation peaks can be possibly attributed to the radical cation formation of $\mathrm{BCCPDQ}$ to $\mathrm{BCCPDQ}^{\bullet+}$ and $\mathrm{BCCPDQ}^{\bullet+}$ to $\mathrm{BCCPDQ}^{\bullet 2+}$ in $\mathrm{N}$ centers. The third oxidation peak at a higher potential can perhaps be assigned to BCCPDQ to BCCPDQ ${ }^{\bullet+}$ oxidation in $\mathrm{N}$ centers attached to a carbonyl group, as there is less electron density compared to other N-centers. The highest occupied molecular orbital (HOMO) and lowest unoccupied molecular orbital (LUMO) energy levels $\left(E_{\text {HOMO }}, E_{\text {LUMO }}\right)$ of the sample were derived from the $\mathrm{CV}$ by picking the relative extreme oxidation ( $\left.E_{\text {onset }}^{\text {ox }}\right)$ and extreme reduction onsets ( $E_{\text {onset }}^{\text {Red }}$ (Fig. $\left.4(\mathrm{a})\right)$ in order to gain better insight into the energy levels along with the band structure. The HOMO and LUMO energy levels and corresponding bandgap were estimated from the empirical equations: ${ }^{56,57}$

$$
\begin{gathered}
E_{\mathrm{LUMO}}=-\left[E_{\text {onset }}^{\mathrm{Red}}-0.49+4.8\right] \mathrm{eV} \text { and } E_{\mathrm{HOMO}} \\
=-\left[E_{\text {onset }}^{\text {ox }}-0.49+4.8\right] \mathrm{eV} \\
\text { Band gap }=E_{\mathrm{LUMO}}-E_{\mathrm{HOMO}}
\end{gathered}
$$

The HOMO and LUMO energy levels were calculated to be -5.687 and $-3.017 \mathrm{eV}$, respectively, utilizing the abovementioned equations. Therefore, the electrochemical bandgap was calculated to be $2.67 \mathrm{eV}$, being in a typical range of semiconducting materials. Using the Kubelka-Munk method, the optical band gap was derived as $\sim 2.68 \mathrm{eV}$, exactly matching the electrochemical measurements. The Kubelka-Munk factor $(K)$ was calculated by using the formula, $K=(1-R)^{2} / 2 R$, where $R$ represents the \% reflectance and $E$ the incident radiation energy. The optical band gap was determined along the intersection point obtained by the extrapolation of lines (Fig. 4(b)).

To gain mechanistic insight concerning the sample's electrochemical process, a scan rate dependent CV study was performed, with the results shown in Fig. 5(a). For a representative redox process, the rate-determining step is the electron transfer on the electrode if the anodic peak current is proportional to the scan rate. Also, the rate-determining step is dependent on the diffusion rate of the electroactive species if it is proportional to the square root of the scan rate. ${ }^{15,58,59}$ To validate this, the anodic peak current densities in the sample were increased accompanied by the step-by-step increase in the scan rate, and the plots of anodic current density $v s$. scan rate and the square root of scan rate were linearly fitted (Fig. 5(b) and (c)) discretely. Herein, the anodic peak current density at $1.06 \mathrm{~V}$ was found to be best fitted with the scan rate as the minimum mean square error $\left(R^{2}\right)$ was closest to $1(0.9962$ in Fig. 5(b) vs. 0.987 in Fig. 5(c)). Accordingly, this culminated in the fact that the redox system is evidently electron transfer controlled.

\subsection{Thermogravimetric analysis (TGA)}

The thermal behavior was analyzed using TGA. BCCPDQ was found to be moisture free and stable up to $\sim 250{ }^{\circ} \mathrm{C}$. The decomposition occurred in a single step, resulting in a weight loss of $67.46 \%$, showing that the sample undergoes a specific weight loss corresponding to a mass of $308.9 \mathrm{~g}$ from the total mass of $458 \mathrm{~g}$. Fig. 6 shows that the two moieties of 1-(cyclopropyl carbonyl) piperazine were decomposed first. A gradual
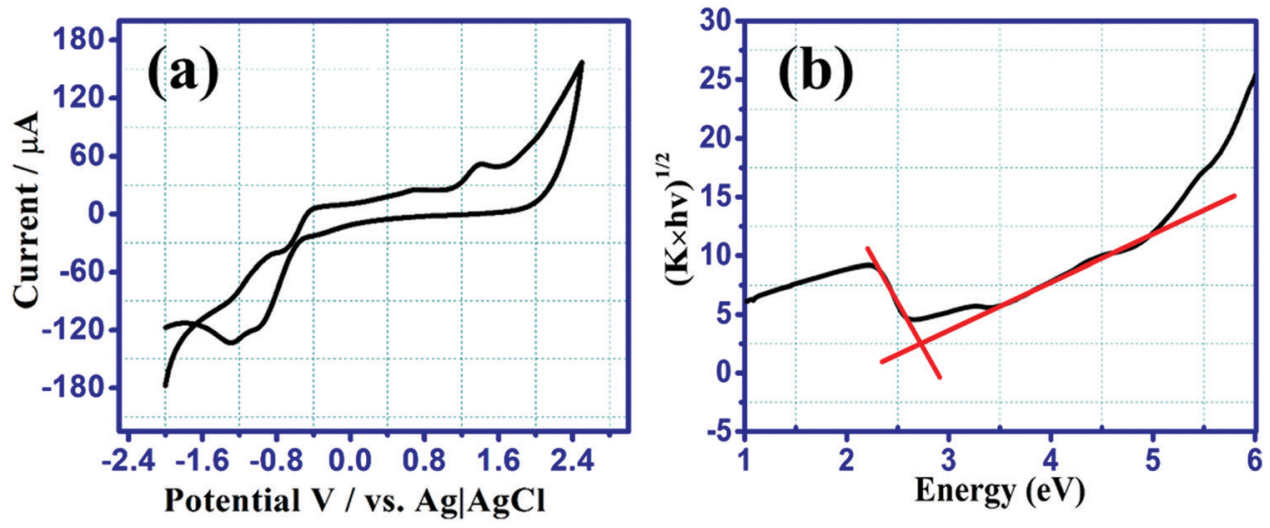

Fig. 4 (a) Cyclic voltammogram of a $10 \mu \mathrm{M}$ of the sample in dry acetonitrile with $0.1 \mathrm{M}$ tetrabutylammonium perchlorate solution as the supporting electrolyte. (b) Kubelka-Munk plot from the DRS spectra revealed the optical band gap to be $\sim 2.68 \mathrm{eV}$. 

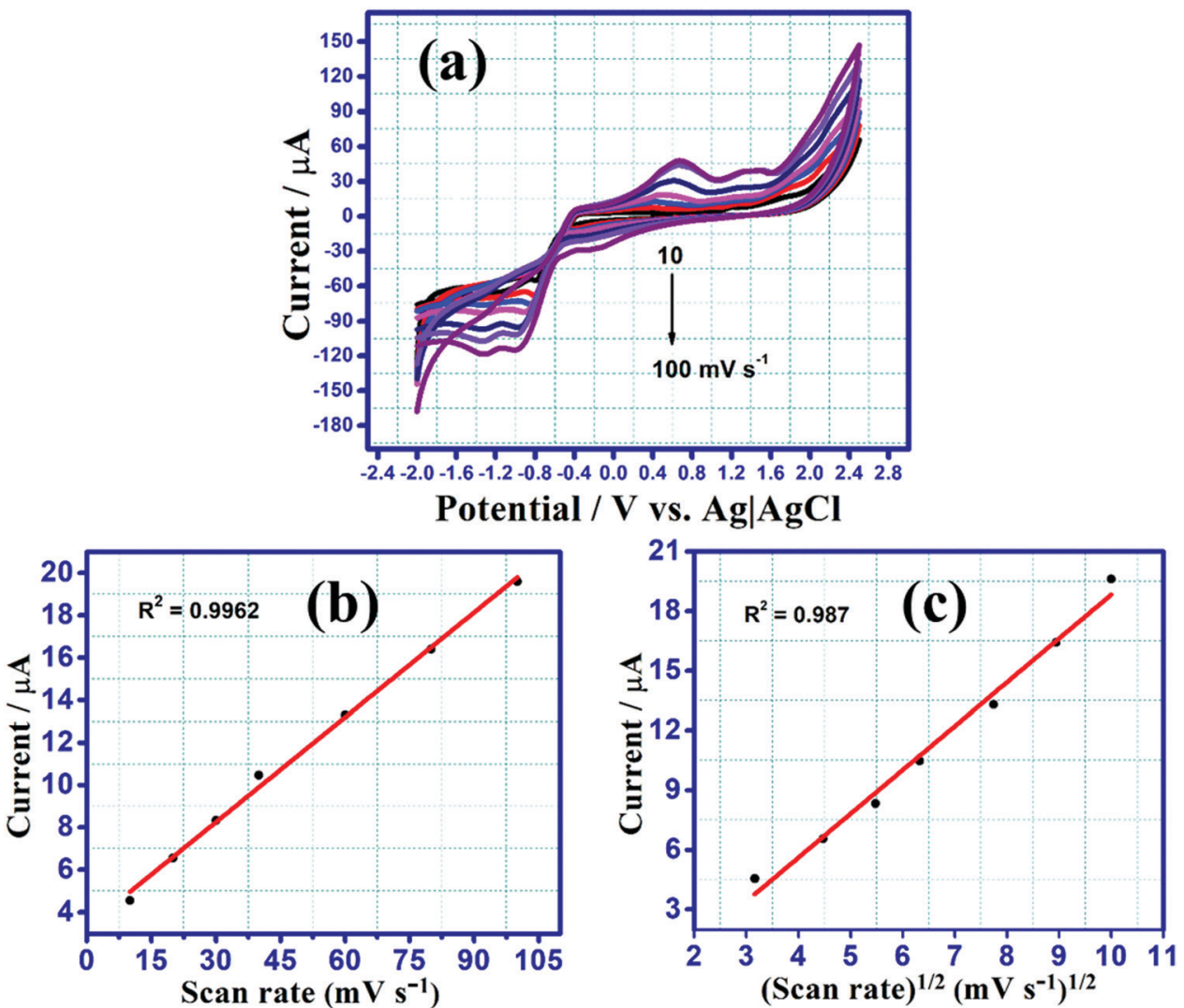

Fig. 5 (a) Scan rate dependent cyclic voltammogram of BCCPDQ at a scan rate from 10 to $100 \mathrm{mV} \mathrm{s}^{-1}$, (b) change in the anodic peak current with scan rate, and (c) the variation in anodic peak current with the square root of the scan rate.

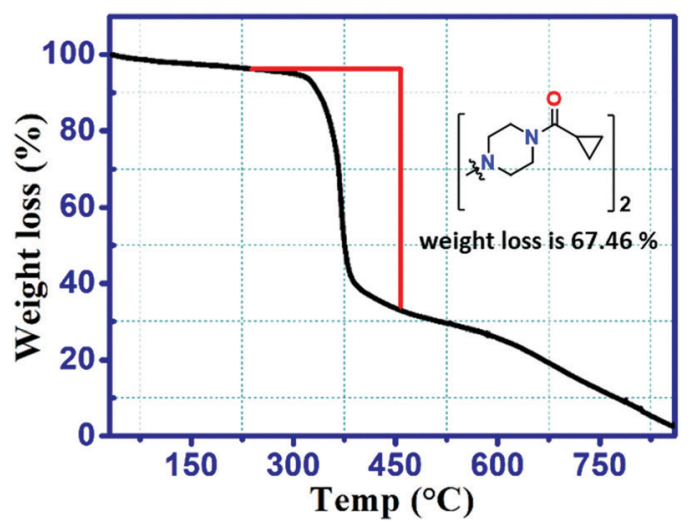

Fig. 6 Thermogram of $\mathrm{BCCPDQ}$ recorded under a $\mathrm{N}_{2}$ atmosphere at a scan rate of $10^{\circ} \mathrm{min}^{-1}$ showing single-step decomposition with two amine moieties, leaving behind the benzenoid ring with dicyanomethylene moiety.

weight loss occurred as the temperature was increased above $250{ }^{\circ} \mathrm{C}$. The final mass left after the entire decomposition process was $32.54 \%$, i.e. $149 \mathrm{~g}$ corresponding to the TCNQ molecule with dicyanomethylene moiety without amine substituents.

Solutions ( $1 \mathrm{mmol}$ ) of the BCCPDQ sample prepared from acetonitrile, methanol, ethanol and IPA, were drop cast on separate silicon wafers and subjected to a morphological study.
The drop cast (a) acetonitrile and (b) methanol clearly exhibit closely packed, uniformly dispersed spherical feature with average particle diameters of 1.71 and $1.43 \mu \mathrm{m}$, respectively. Densely arranged spheres were observed in (a) compared to (b), while, (c) from ethanol and (d) from IPA manifested in a combination of spherical/isolated particles and an irregular non-uniform nature (Fig. S8, ESI $\dagger$ ) with particle diameters of 0.68 and $0.75 \mu \mathrm{m}$, respectively. Such a variation in morphology can probably be assigned as being due to the different evaporation rates of solvents with different polarities, and the consequent molecular assembly emanating from the solventmolecule interactions with solvent diffusion capability, resulting in different growth kinetics. ${ }^{15,49}$ Notably, although sphere-shaped particles in pure acetonitrile has been found to be a characteristic of amorphous nanoparticles formed by DADQ derivatives with aromatic substituents connected by conformationally labile bonds, ${ }^{60}$ herein, interestingly we observed sphere-shaped particles in various solvents (Fig. S8, ESI $\dagger$ ) for BCCPDQ with an aliphatic substituent amine.

\subsection{Solar cell application}

3.5.1. Absorption and emission studies of film. The UVvisible absorbance and emission spectra of the plain BCCPDQ and $\mathrm{TiO}_{2}$ /BCCPDQ films are shown in Fig. 7(a) and (b). The maximum absorption for the pure BCCPDQ films is observed at $390 \mathrm{~nm}$, whereas a broader absorption was attained for the 

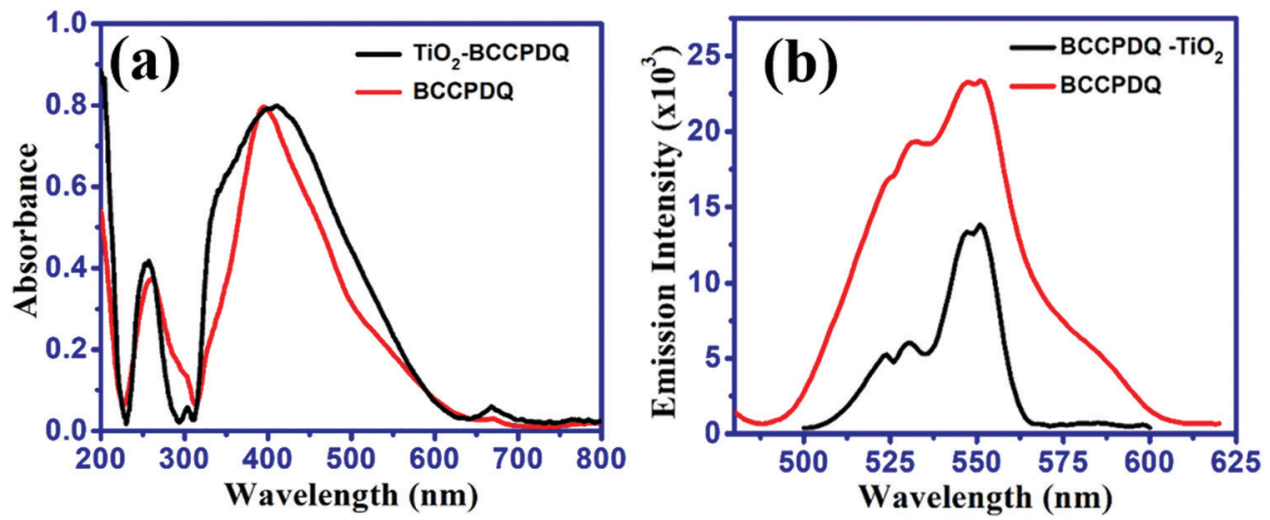

Fig. 7 (a) Absorption spectroscopy of both plain and $\mathrm{TiO}_{2}$-coated $\mathrm{BCCPDQ}$, spin coated on an ITO-PET substrate. (b) Emission spectroscopy of both films. The wavelength of the maximum emission observed at $550 \mathrm{~nm}$ was the same for both films. Enhancement of the fluorescence was observed for the $\mathrm{TiO}_{2} / \mathrm{BCCPDQ}$ film compared to the BCCPDQ film.

tandem film and the peak maximum was red shifted to $415 \mathrm{~nm}$ owing to improved $\pi-\pi$ intermolecular stacking. Photoluminescence spectroscopy measurements were carried out to explain the carrier entrapment and transport phenomena of photogenerated carriers (PL), as shown in Fig. 7(b). The lower emission intensity of $\mathrm{TiO}_{2} / \mathrm{BCCPDQ}$ compared to plain BCCPDQ reveals the presence of sub-bands or surface intermittent states, beneficial for the separation of photoinduced charge carriers, which promote the transport of electron-hole pairs. Similar results have also been reported by Liu et al. ${ }^{61}$ where surface bismuth vacancies promoted the transfer of photo-excited carriers, thereby inhibiting the rate of recombination.

3.5.2. Photovoltaic properties. A small molecule OSC device with a conventional structure of Al/BCCPDQ/ITO-PET was fabricated, as shown in Fig. 8(a). In order to observe the photovoltaic characteristics, current-voltage $(I-V)$ measurements were performed on the device under an irradiation of 1 sun and air mass (AM) $1.5 \mathrm{G}$, which are the standard test conditions Fig. 8(b). The device, as shown in Fig. 8(b), revealed a short circuit current density $\left(J_{\mathrm{sC}}\right)$ and an open circuit voltage $\left(V_{\mathrm{OC}}\right)$ of $2.56 \mathrm{~mA} \mathrm{~cm}{ }^{-2}$ and $0.50 \mathrm{~V}$, respectively, upon a voltage sweep from -1 to $1 \mathrm{~V}$. The maximum voltage $\left(V_{\mathrm{M}}\right)$ of the device was found to be $0.25 \mathrm{~V}$ and the maximum current density $\left(J_{\mathrm{M}}\right)$ observed was $1.445 \mathrm{~mA} \mathrm{~cm}{ }^{-2}$. The fill factor (FF) value was obtained by dividing the maximum power from the PV unit sample with the product of $V_{\mathrm{OC}}$ and $J_{\mathrm{SC}}$ deduced to be $29.4 \%$. The power conversion efficiency (PCE, $\eta$ ) of the cell is defined as the ratio of the total output power to the input irradiated power given by: (open circuit voltage, $V_{\text {oc }}$, short circuit current, $J_{\mathrm{sc}}$, power input, $P_{\mathrm{in}}$, fill factor, $\mathrm{FF}$ )

$$
\text { Efficiency } \eta=\frac{V_{\mathrm{OC}} \times J_{\mathrm{sc}} \times \mathrm{FF}}{P_{\text {in }}}
$$

The $\eta$ of the plain BCCPDQ standalone device with a dimension of $1 \mathrm{~cm}^{2}$ per unit cell was obtained to be $0.40 \%$. This low PCE can be attributed to the small collecting electric field, which leads to the recombination of photogenerated charge carriers inside the active layer. Therefore, to counter the rapid recombination rate of the device, $\mathrm{TiO}_{2} \mathrm{NPs}$ as an electron transport layer (ETL) were incorporated between the BCCPDQ and the ITO-PET layers (Fig. 9(a)).

The ETL plays a significant role in the extraction and transportation of photoinduced charge carriers from the active BCCPDQ layer to the anode or cathode. ${ }^{62}$ Simultaneously, the ETL also transforms the interface properties between the photon generated layer and the electrode, thereby minimizing the rate of recombination. Furthermore, the NPs, due to their increased surface area-to-volume ratio, improve the contact properties and enhance charge diffusion by facilitating directional transportation of the charges. ${ }^{62,63}$

The $\mathrm{TiO}_{2}$ NP-embedded BCCPDQ PV cell, as shown in Fig. 9(b), exhibited a $J_{\mathrm{SC}}$ and $V_{\mathrm{OC}}$ of $6.72 \mathrm{~mA} \mathrm{~cm}^{-2}$ and $1 \mathrm{~V}$, respectively. The attained $V_{\mathrm{M}}$ and $J_{\mathrm{M}}$ values were $0.54 \mathrm{~V}$ and $3.68 \mathrm{~mA} \mathrm{~cm}{ }^{-2}$, respectively. The $\mathrm{FF}$ value realized from the obtained parameters was $33.6 \%$ and the efficiency was obtained to be $2.26 \%$, which represents an around 10 -fold enhancement compared to plain BCCPDQ PV. The increase in the PCE value can possibly be ascribed to the alteration of the interfacial junction between the $\mathrm{BCCPDQ} / \mathrm{TiO}_{2} \mathrm{NPs}$, which undergoes trap passivation due to the alignment of the bandgap states between both the layers. This increases the electric field at the depletion region, thereby resulting in swift charge migration across the junction. The increase in the FF value is due to the reduction in the series resistance $\left(R_{\mathrm{S}}\right)$ owing to the formation of the junction. The PV properties of the two devices were compiled and are presented in Table 1. Furthermore, the relevant data representing the efficiencies of other recently developed small molecules utilized for solar cell application are summarized in Table S11 (ESI $\dagger$ ). These publications do not directly employ the small molecule, but they do include details about produced devices, including doping, annealing, and other processes. Currently, however, BCCPDQ does not need the above modifications and may be used directly in the OSC application.

3.5.3. Band diagram. An energy band diagram (Fig. 10) was constructed to describe the phenomena occurring at the PV cell 

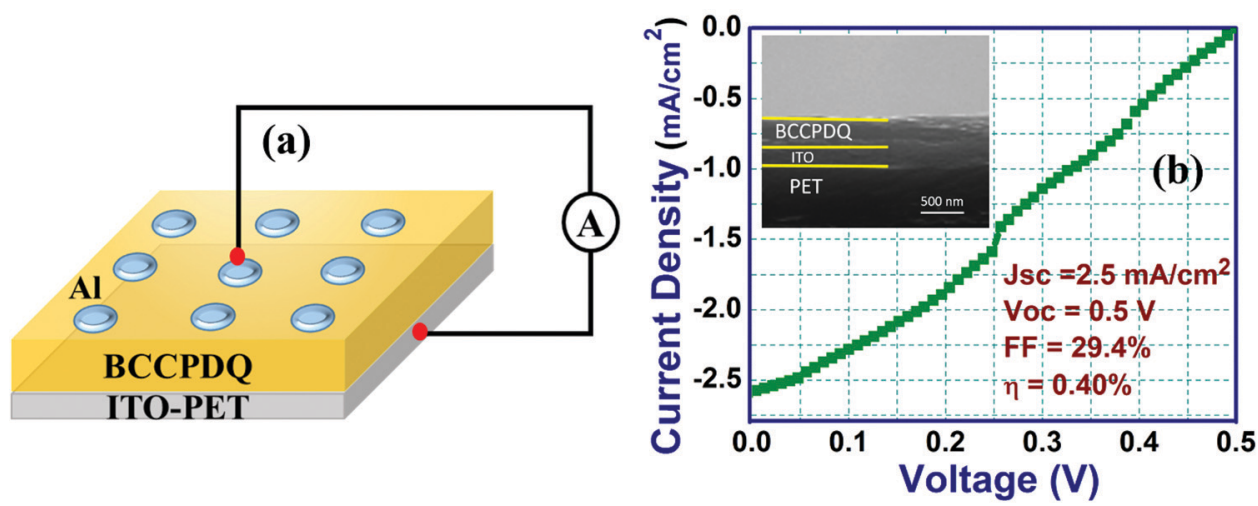

Fig. 8 (a) Schematic of the plain BCCPDQ PV device with aluminum top electrodes. (b) J-V characteristics obtained under 1 sun and air mass (AM) 1.5 standard test conditions. The inset shows a cross section of the PV device with the thickness of the BCCPDQ layer at around $430 \mathrm{~nm}$.
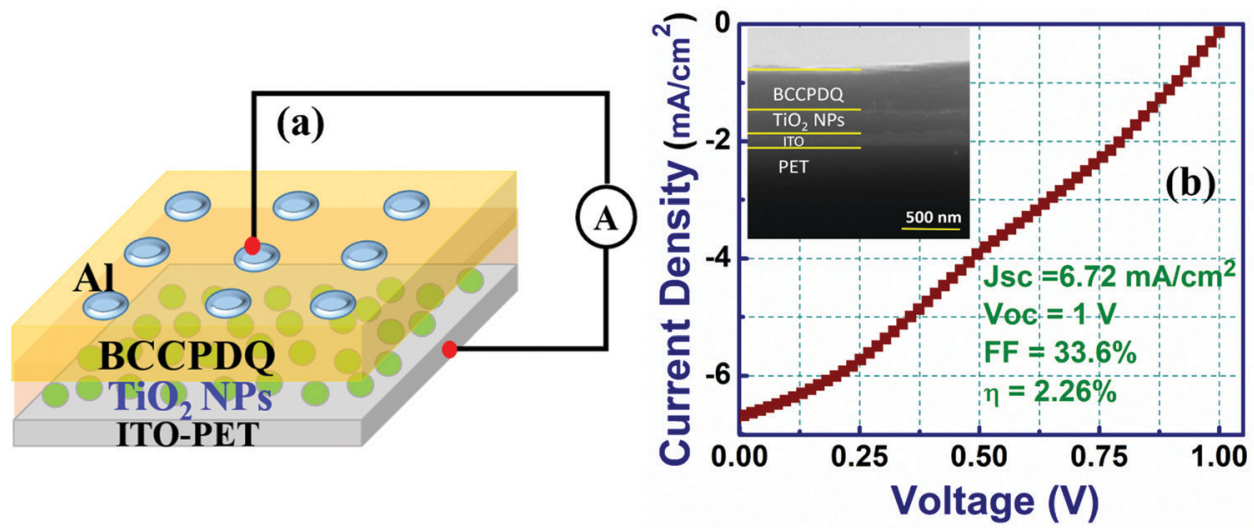

Fig. 9 (a) Schematic of the $\mathrm{TiO}_{2} \mathrm{NP}$-incorporated BCCPDQ PV device. (b) J-V characteristics obtained under 1 sun and AM 1.5 standard test conditions for the Al/BCCPDQ/TiO 2 NPs/ITO. The inset shows the cross-sectional micro-image of the PV device, where the thickness of the BCCPDQ is around $430 \mathrm{~nm}$ and the $\mathrm{TiO}_{2}$ NPs are $215 \mathrm{~nm}$ thick.

Table 1 Comparative summary of the photovoltaic (PV) properties of the plain $\mathrm{BCCPDQ}$ and $\mathrm{TiO}_{2} \mathrm{NP}$-incorporated $\mathrm{BCCPDQ} \mathrm{PV}$ devices

\begin{tabular}{lllll}
\hline Device & $\begin{array}{l}J_{\mathrm{SC}} \\
\left(\mathrm{mA} \mathrm{cm}^{-2}\right)\end{array}$ & $\begin{array}{l}V_{\mathrm{OC}} \\
(\mathrm{V})\end{array}$ & $\mathrm{FF}$ & $\begin{array}{l}\text { Efficiency } \\
(\%)\end{array}$ \\
\hline $\mathrm{Al} / \mathrm{BCCPDQ} / \mathrm{ITO}-\mathrm{PET}$ & 2.56 & 0.5 & 0.294 & 0.40 \\
$\mathrm{Al} / \mathrm{BCCPDQ} / \mathrm{TiO}_{2}$ NPs/ITO-PET & 6.72 & 1 & 0.336 & 2.26
\end{tabular}

interface in order to gain a deeper understanding of the measured $J-V$ characteristics. When the plain BCCPDQ layer was sandwiched between the top and bottom electrodes, the weak electric field created internally generated photoinduced excitons, which undergo rapid recombination as they hop towards the electrodes. Hence, low $V_{\mathrm{OC}}$ and $J_{\mathrm{SC}}$ values were observed for the standalone device. In contrast, the energy level offset between the valence band (VB) and the conduction band (CB) of BCCPDQ and the $\mathrm{TiO}_{2}$ NPs facilitated charge separation at the interface. For efficient charge collection, the bottom electrode aligned energetically with the junction to form an ohmic contact. When a reverse bias was applied on the device under illuminated conditions, excitons generated in the photoactive $\mathrm{BCCPDQ}$ layer diffused to the $\mathrm{BCCPDQ} / \mathrm{TiO}_{2} \mathrm{NP}$ interface to be dissociated by the internally formed electric field. As a result, both edges of the bands yielded and bending of the bands expedited the carrier separation process. Subsequently, the $\mathrm{TiO}_{2} \mathrm{NPs}$, which formed an intimate interfacial contact with the photoactive layer owing to their large surface area, provided an efficient channel for charge extraction and transport of electrons to the electrode. This limited the rate of recombination of the electrons at the $\mathrm{BCCPDQ} / \mathrm{TiO}_{2} \mathrm{NP}$ interface.

The high Fermi level offset at the Al top electrode/BCCPDQ junction, however, caused band bending and created a Schottky barrier speeding hole extraction from the photoactive layer, limiting recombination at the interface. Therefore, higher PV performance was observed for the $\mathrm{Al} / \mathrm{BCCPDQ} / \mathrm{TiO}_{2} \mathrm{NPs} / \mathrm{ITO}$ PET device when compared to the plain device. It is noteworthy to mention that the higher optical properties attained for the heterojunction also contribute significantly to the photovoltaic properties of the cell.

3.5.4. Stability analysis. As established, the efficacy of the flexible PV device is dependent on the reproducibility of the 


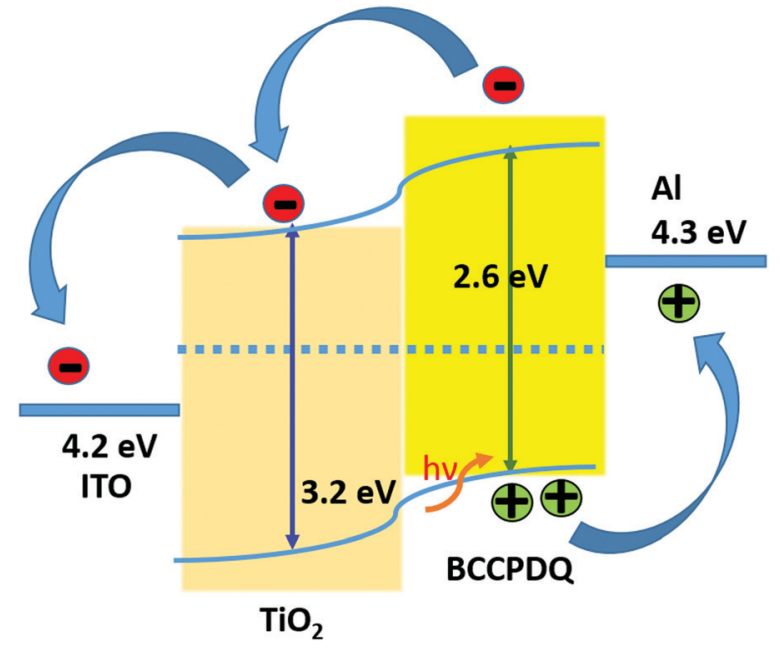

Fig. 10 Band diagram describing the generation of excitons, and their separation and extraction phenomena occurring inside the PV cell device. The $\mathrm{TiO}_{2} \mathrm{NPs}$ as an ETL facilitated efficient passage of electrons to the bottom ITO electrode, thereby reducing the recombination rate of electrons and holes.

electrical properties under varying bend conditions. Therefore, the influence of tensile and compressive bending curvatures on the $\mathrm{PV}$ performance of the $\mathrm{Al} / \mathrm{BCCPDQ} / \mathrm{TiO}_{2} \mathrm{NPs} / \mathrm{ITO}-\mathrm{PET}$ was device investigated. Fig. 11(a) and (b) represent the compressive flexure or upward bending of the sample for which the $J-V$ characteristics were extracted under illuminated conditions of 1 sun and AM 1.5 G standard test conditions.

Interestingly, the electrical properties of the PV device under tensile bending (Fig. 11(c)) were found to be almost similar compared to those of the neutrally bent device scanned from -1 to $1 \mathrm{~V}$. Alike characteristics were retained when the PV unit cell underwent tensile flexure or downward bending. Fig. 11(c) and (d) confirm that the device is robust and reliable, with both factors playing a key role in roll-to-roll processing in low power wearable electronics. A slight increase in the current density was observed when the bending was at its maximum, which might be due to the sudden increase in the resistance of the substrate, however when the device was brought back to the normal position, the $J-V$ characteristics were found to be maintained.

The stability of the fabricated solar cell was investigated for over $100 \mathrm{~h}$ (Fig. 12). Testing was performed under 1 sun $\left(100 \mathrm{~mW} \mathrm{~cm}{ }^{-2}\right)$ illumination at air mass $1.5 \mathrm{G}$. In the initial hours $(<20 \mathrm{~h})$ the cell showed a consistent PCE, with excellent stability and almost no photodegradation. Moreover, the variation in the temperature due to the outside climate ranged
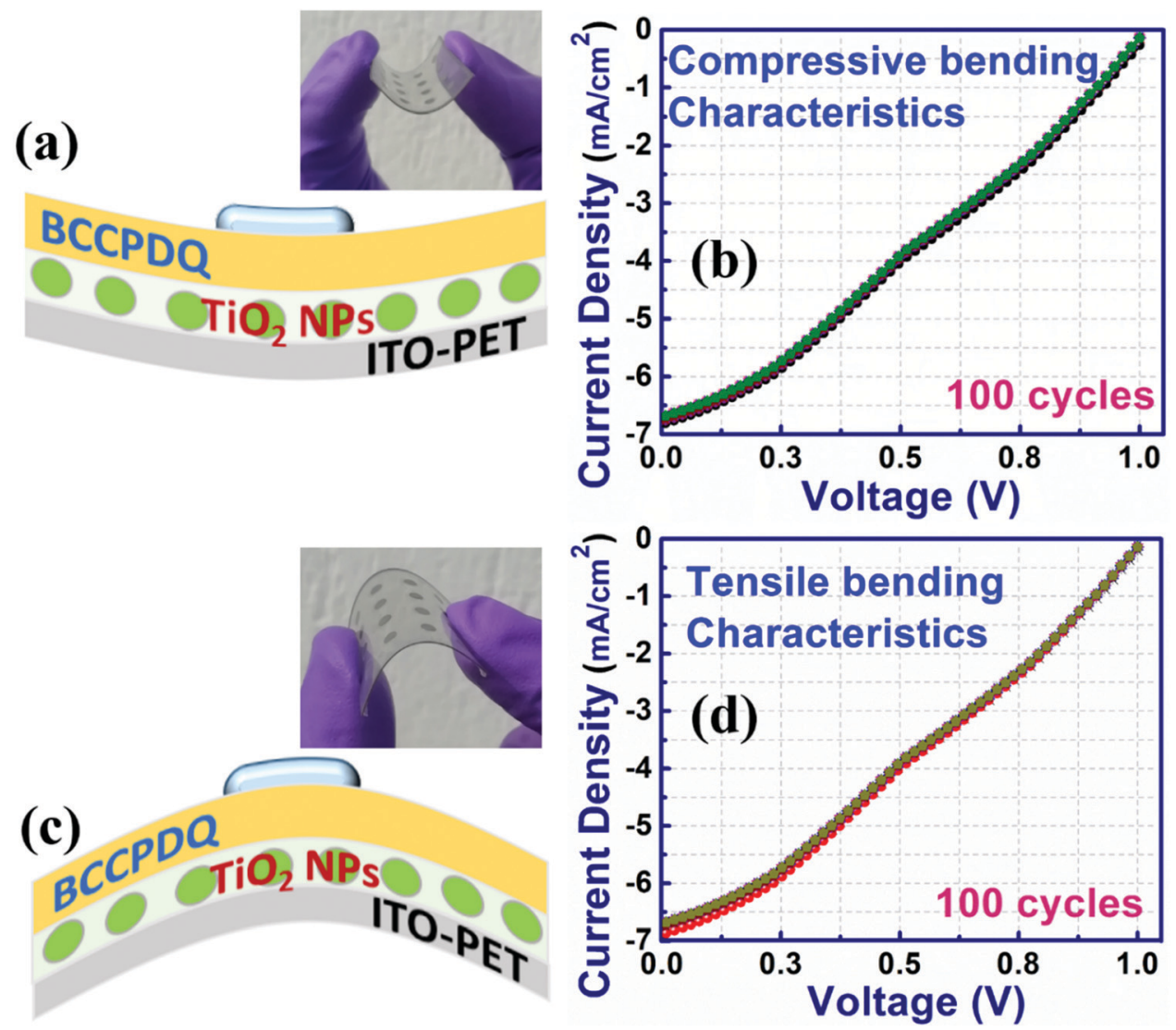

Fig. 11 Flexure/bending tests performed on the Al/BCCPDQ/TiO $2 \mathrm{NPs} / \mathrm{ITO}-\mathrm{PET}$ device. (a) Schematic of the device undergoing compressive bending. (b) $J-V$ characteristics measured under 1 sun and AM 1.5 standard test conditions in compressive bending states. (c) Schematic of the device when undergoing tensile bending. (d) $J-V$ characteristics measured under 1 sun and AM 1.5 standard test conditions under tensile bending conditions. 


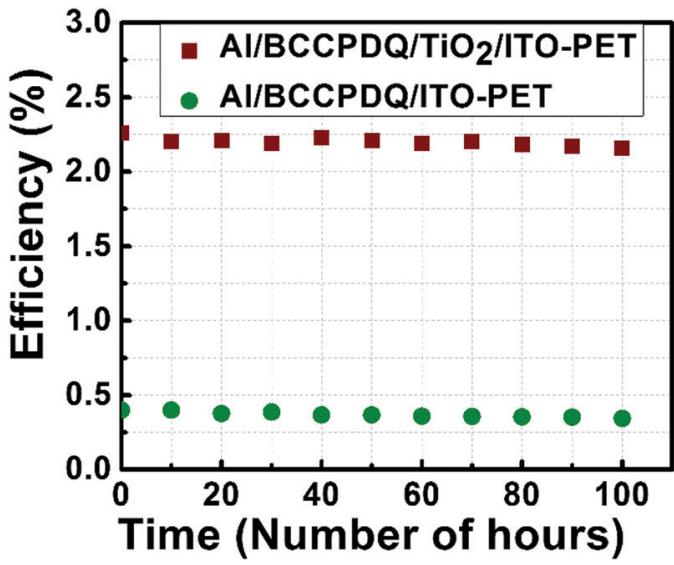

Fig. 12 Stability analysis showing the dependence of efficiency on the number of hours the device has been exposed to illumination, and its retention over time gives us the information about the stability of the device.

between 25 and $30{ }^{\circ} \mathrm{C}$, for which barely any change in the PCE was observed. Due to continued exposure to light and the transient effects generated by the heat, the aging of the heterojunction occurred earlier than that of the plain BCCPDQ cell. However, the percentage of degradation was still lower and even after $100 \mathrm{~h}$ the $\mathrm{Al} / \mathrm{BCCPDQ} / \mathrm{TiO}_{2} / \mathrm{ITO}$ cell exhibited $94 \%$ of its initial efficiency.

\section{Conclusion}

TCNQ derivatives, obtained with primary/secondary/simple aromatic amines as substituents were explored in terms of their optical and non-linear optical properties. Very few piperazine derivatives of TCNQ are known, among which a limited number have exhibited distinct features. For instance, $\mathrm{N}$ methyl piperazine has shown aggregation enhanced fluorescence, a phenyl carbonyl piperazine derivative has unveiled phosphorescence due to its carbonyl functionality, and a hydroxyethyl piperazine derivative has manifested a resistive switching memory device application. Herein, utilization of 1-(cyclopropylcarbonyl)piperazine resulted in the formation of photoluminescent and thermally stable $\left(\sim 250{ }^{\circ} \mathrm{C}\right)$ 7,7-bis(1-cyclopropylcarbonylpiperazino)-8,8-dicyanoquinodimethane (BCCPDQ) via a facile single step synthesis. BCCPDQ manifested contrasting properties, resulting in supramolecular assemblies driven by extensive short contacts, and H-bonding among the water, DMF and BCCPDQ molecular dipoles. CV disclosed three consecutive quasi-reversible reductions of the dicyano part into correspondent radical anions. Three irreversible oxidation peaks were also noted, attributed to the donor 1-(cyclopropyl carbonyl) piperazine group in the sample. Moreover, BCCPDQ exhibited unprecedented solar cell application capability, among the TCNQ derivatives known so far. BCCPDQ-based heterojunction devices with and without $\mathrm{TiO}_{2}$ NPs were fabricated on flexible substrates to demonstrate the $\mathrm{PV}$ properties, using $\mathrm{Al}$ as the top contact and ITO as the bottom. The OSC device with $\mathrm{TiO}_{2}$ NPs manifested excellent stability under tensile and compressive stress, showing a PCE of $2.26 \%$, representing a $\sim 10$ fold improvement over the plain standalone device. The electrical findings were verified with and without bending the devices, and minimal variation was observed, signifying the material's suitability for use in flexible optoelectronic applications. A comprehensive band diagram displaying the operating mechanism of the manufactured PV device was constructed. The choice of 1-(cyclopropyl carbonyl) piperazine possessing an aliphatic (cyclopropyl) moiety and a carbonyl functionality (unlike phenylcarbonyl piperazine), produced a distinctive TCNQ derivative that exhibits fluorescence in solution $\left(\Phi_{\mathrm{f}}=\sim 0.30 \%\right)$ as well as in its solid state $\left(\Phi_{\mathrm{f}}=\sim 10 \%\right)$, and flexible small organic molecule based solar cell application proficiency. The current work establishes commencement towards the design and development of futuristic flexible solution-processed organic solar cell devices, especially those based on TCNQ derivatives, which have not yet been explored and remain as a gap in knowledge amidst the research on TCNQ related molecules.

\section{Author contributions}

The manuscript was overall written, handled and edited by Subbalakshmi Jayanty, except for the solar cell part, which was written by $\mathrm{H}$ Renuka. Anwarhussaini Syed: data curation, investigation, validation $\mathrm{H}$ Renuka: data curation, investigation validation Anuradha Mohitkar: investigation Raghaviah Pallepogu: formal analysis Mahadev Sai Karthik Challa: investigation Sanket Goel: methodology, resources Subbalakshmi Jayanty: conceptualization, funding acquisition, investigation, methodology, resources, supervision, validation, project administration, writing - original draft, writing - review \& editing.

\section{Conflicts of interest}

Authors do not have conflict of interest to declare.

\section{Acknowledgements}

SJ thanks Mr K. Shekhar, NIT Warangal, for helping with the electrochemical study. SJ also thanks Prof. S. Mishra, Department of Chemistry IIT Kharagpur for extending help with the autocorrelation data. Department of Science and Technology (DST), Govt. India is highly acknowledged by SJ for the financial support under funded project (DST-EMR/2016/002209). The Central Analytical Laboratory (CAL) facility provided by the BITS-Pilani, Hyderabad campus and the DST-FIST grant facility sanctioned to the Department of Chemistry, BITS-Pilani Hyderabad Campus are also highly acknowledged. 


\section{References}

1 J. Ferraris, D. O. Cowan, V. Walatka and J. H. Perlstein, J. Am. Chem. Soc., 1973, 95, 948-949.

2 H. Alves, A. S. Molinari, H. Xie and A. F. Morpurgo, Nat. Mater., 2008, 7, 574-580.

3 K. P. Goetz, D. Vermeulen, M. E. Payne, C. Kloc, L. E. McNeil and O. D. Jurchescu, J. Mater. Chem. C, 2014, 2, 3065-3076.

4 X. Qu, J. Lu, C. Zhao, J. F. Boas, B. Moubaraki, K. S. Murray, A. Siriwardana, A. M. Bond and L. L. Martin, Angew. Chem., Int. Ed., 2011, 50, 1589-1592.

5 N. Senthilnathan and T. P. Radhakrishnan, Chem. Mater., 2020, 32, 8567-8575.

6 M. Szablewski, P. R. Thomas, A. Thornton, D. Bloor, G. H. Cross, J. M. Cole, J. A. K. Howard, M. Malagoli, F. Meyers, J.-L. Brédas, W. Wenseleers and E. Goovaerts, J. Am. Chem. Soc., 1997, 119, 3144-3154.

7 A. Patra, N. Venkatram, D. N. Rao and T. P. Radhakrishnan, J. Phys. Chem. C, 2008, 112, 16269-16274.

8 P. Sudhakar and T. P. Radhakrishnan, Chem. - Asian J., 2019, 14, 4754-4759.

9 C. G. Chandaluri and T. P. Radhakrishnan, Opt. Mater., 2011, 34, 119-125.

10 C. G. Chandaluri, A. Patra and T. P. Radhakrishnan, Chem. Eur. J., 2010, 16, 8699-8706.

11 S. Jayanty and T. P. Radhakrishnan, Chem. - Eur. J., 2004, 10, 2661-2667.

12 N. Senthilnathan, C. G. Chandaluri and T. P. Radhakrishnan, Sci. Rep., 2017, 7, 10583-10593.

13 N. Senthilnathan, K. Gaurav, C. Venkata Ramana and T. P. Radhakrishnan, J. Mater. Chem. B, 2020, 8, 4601-4608.

14 A. Ali, K. Gaurav, N. Senthilnathan, T. P. Radhakrishnan, C. Sasikala and C. V. Ramana, J. Microbiol. Methods, 2020, 177, 106019-106024.

15 A. Syed, H. Battula, P. K. R. Boppidi, S. Kundu, C. Chakraborty and S. Jayanty, Org. Electron., 2020, 76, 105457-105468.

16 Z. Yang, Z. Mao, X. Zhang, D. Ou, Y. Mu, Y. Zhang, C. Zhao, S. Liu, Z. Chi, J. Xu, Y.-C. Wu, P.-Y. Lu, A. Lien and M. R. Bryce, Angew. Chem., 2016, 128, 2221-2225.

17 P. Sudhakar and T. P. Radhakrishnan, J. Mater. Chem. C, 2019, 7, 7083-7089.

18 I. Paci, J. C. Johnson, X. Chen, G. Rana, D. Popović, D. E. David, A. J. Nozik, M. A. Ratner and J. Michl, J. Am. Chem. Soc., 2006, 128, 16546-16553.

19 E. C. Greyson, B. R. Stepp, X. Chen, A. F. Schwerin, I. Paci, M. B. Smith, A. Akdag, J. C. Johnson, A. J. Nozik, J. Michl and M. A. Ratner, J. Phys. Chem. B, 2010, 114, 14223-14232.

20 L. Nian, K. Gao, Y. Jiang, Q. Rong, X. Hu, D. Yuan, F. Liu, X. Peng, T. P. Russell and G. Zhou, Adv. Mater., 2017, 29, 1700616-1700622.

21 Y. Lin, Y. Firdaus, F. H. Isikgor, M. I. Nugraha, E. Yengel, G. T. Harrison, R. Hallani, A. El-Labban, H. Faber, C. Ma, X. Zheng, A. Subbiah, C. T. Howells, O. M. Bakr, I. McCulloch, S. D. Wolf, L. Tsetseris and T. D. Anthopoulos, ACS Energy Lett., 2020, 5, 2935-2944.
22 X. He, L. Yin and Y. Li, J. Mater. Chem. C, 2019, 7, 2487-2521.

23 A. A. Mohamad, Sol. Energy, 2019, 190, 434-452.

24 U. Mehmood, S. Rahman, K. Harrabi, I. A. Hussein and B. V. S. Reddy, Adv. Mater. Sci. Eng., 2014, 2014, 1-12.

25 R. Yu, H. Yao, L. Hong, M. Gao, L. Ye and J. Hou, J. Mater. Chem. C, 2020, 8, 44-49.

26 C. Liu, Z. Li, Z. Zhang, X. Zhang, L. Shen, W. Guo, L. Zhang, Y. Long and S. Ruan, Phys. Chem. Chem. Phys., 2017, 19, 245-250.

27 Y. Zhang, H. Zhou, J. Seifter, L. Ying, A. Mikhailovsky, A. J. Heeger, G. C. Bazan and T.-Q. Nguyen, Adv. Mater., 2013, 25, 7038-7044.

28 F. Guillain, J. Endres, L. Bourgeois, A. Khan, L. Vignau and G. Wantz, ACS Appl. Mater. Interfaces, 2016, 8, 9262-9267.

29 K. Fukuda, K. Yu and T. Someya, Adv. Energy Mater., 2020, 10, 2000765-2000774.

30 T. Lei, R. Peng, W. Song, L. Hong, J. Huang, N. Fei and Z. Ge, J. Mater. Chem. A, 2019, 7, 3737-3744.

31 I. D. W. Samuel and G. A. Turnbull, Chem. Rev., 2007, 107, 1272-1295.

32 I. D. W. Samuel and G. A. Turnbull, Mater. Today, 2004, 7, 28-35.

33 A. Ekbote, S. H. Han, T. Jadhav, S. M. Mobin, J. Y. Lee and R. Misra, J. Mater. Chem. C, 2018, 6, 2077-2087.

34 K. Müllen and U. Scherf, Organic Light Emitting Devices, Wiley, 2005.

35 J. B. Arockiam and S. Ayyanar, Sens. Actuators, B, 2017, 242, 535-544.

36 S. Fan, J. Lai, P. L. Burn and P. E. Shaw, ACS Sens., 2019, 4, 134-142.

37 X. Hou, C. Ke, C. J. Bruns, P. R. McGonigal, R. B. Pettman and J. F. Stoddart, Nat. Commun., 2015, 6, 6884-6892.

38 J. Yuan, P. R. Christensen and M. O. Wolf, Chem. Sci., 2019, 10, 10113-10121.

39 R. Yu, H. Yao, L. Hong, M. Gao, L. Ye and J. Hou, J. Mater. Chem. C, 2020, 8(1), 44-49.

40 J. N. Demas and G. A. Crosby, J. Phys. Chem., 1971, 75, 991-1024.

41 A. Patra, N. Hebalkar, B. Sreedhar, M. Sarkar, A. Samanta and T. P. Radhakrishnan, Small, 2006, 2, 650-659.

42 O. V. Dolomanov, L. J. Bourhis, R. J. Gildea, J. A. K. Howard and H. Puschmann, J. Appl. Crystallogr., 2009, 42, 339-341.

43 G. M. Sheldrick, Acta Crystallogr., Sect. A: Found. Crystallogr., 2008, 64, 112-122.

44 G. M. Sheldrick, Acta Crystallogr., Sect. C: Struct, Chem., 2015, 71, 3-8.

45 A. Patra and T. P. Radhakrishnan, Chem. - Eur. J., 2009, 15, 2792-2800.

46 P. Raghavaiah, R. Kuladeep, D. Narayana Rao, A. Jyothi Lakshmi, P. Srujana and J. Subbalakshmi, Acta Crystallogr., Sect. B: Struct. Sci., Cryst. Eng. Mater., 2016, 72, 709-715.

47 P. Srujana, T. Gera and T. P. Radhakrishnan, J. Mater. Chem. C, 2016, 4, 6510-6515.

48 S. Jayanty and T. P. Radhakrishnan, Chem. - Eur. J., 2004, 10, 791-797. 
49 A. Boyineni and S. Jayanty, Dye. Pigm., 2014, 101, 303-311.

50 D. Bloor, Y. Kagawa, M. Szablewski, M. Ravi, S. J. Clark, G. H. Cross, L. O. Pålsson, A. Beeby, C. Parmer and G. Rumbles, J. Mater. Chem., 2001, 11, 3053-3062.

51 J. R. Lakowicz, Principles of Fluorescence Spectroscopy, Springer US, Boston, 2006.

52 A. Patra, C. G. Chandaluri and T. P. Radhakrishnan, Nanoscale, 2012, 4, 343-359.

53 P. Srujana, P. Sudhakar and T. P. Radhakrishnan, J. Mater. Chem. C, 2018, 6, 9314-9329.

54 S. Anwarhussaini, B. Himabindu, S. Mishra and S. Jayanty, ACS Omega, 2021, 6, 3090-3105.

55 D. F. Perepichka, M. R. Bryce, C. Pearson, M. C. Petty, E. J. L. McInnes and J. P. Zhao, Angew. Chem., Int. Ed., 2003, 42, 4636-4639.

56 M. L. Keshtov, S. A. Kuklin, N. A. Radychev, A. Y. Nikolaev, I. E. Ostapov, M. M. Krayushkin, I. O. Konstantinov,
E. N. Koukaras, A. Sharma and G. D. Sharma, Phys. Chem. Chem. Phys., 2016, 18, 8389-8400.

57 C. Chakraborty, A. Layek, P. P. Ray and S. Malik, Eur. Polym. J., 2014, 52, 181-192.

58 S. Halder, S. Roy and C. Chakraborty, Sol. Energy Mater. Sol. Cells, 2022, 234, 111429-111437.

59 C. W. Hu, T. Sato, J. Zhang, S. Moriyama and M. Higuchi, ACS Appl. Mater. Interfaces, 2014, 6, 9118-9125.

60 C. G. Chandaluri and T. P. Radhakrishnan, Angew. Chem., Int. Ed., 2012, 51, 11849-11852.

61 G. Liu, P. Niu, C. Sun, S. C. Smith, Z. Chen, G. Q. (Max) Lu and H.-M. Cheng, J. Am. Chem. Soc., 2010, 132, 11642-11648.

62 S. Zheng, G. Wang, T. Liu, L. Lou, S. Xiao and S. Yang, Sci. China: Chem., 2019, 62, 800-809.

63 F. Shahvaranfard, M. Altomare, Y. Hou, S. Hejazi, W. Meng, B. Osuagwu, N. Li, C. J. Brabec and P. Schmuki, Adv. Funct. Mater., 2020, 30, 1909738-1909746. 